\title{
LA RESPONSABILIDAD ESTATAL EN EL ACTUAL ESTADO DE DERECHO
}

\author{
Carlos E. Delpiazzo*
}

\begin{abstract}
Resumen
La generación de entidades o personas jurídicas - entes instrumentales de la administración - para vehiculizar un cambio de régimen de las actividades asignadas a la administración pública, tiene por objeto huir del derecho administrativo, y por tanto, hacer inviable la responsabilidad estatal. Sin embargo, esto desnaturaliza la propia razón de ser de los entes públicos estatales, pues no tiene sentido eximir de responsabilidad al Estado cuando la actividad prestacional que causa el daño ha sido puesta por él en manos del tercero que la ejerce. Frente a ello, y considerando que una sociedad que no reconozca que la Administración pública debe servir a los objetivos generales con sometimiento pleno al derecho, "o que reconociéndolo, le agregue reservas o excepciones, no vive verdaderamente bajo un régimen de Estado de derecho" (Duguit), se ha postulado la "comunicabilidad" de la responsabilidad, de modo que el ciudadano lesionado por un ente instrumental no se vea privado de una justa reparación.
\end{abstract}

Palabras clave: Responsabilidad estatal - Administración pública - Derecho administrativo - Administración instrumental - Estado de derecho Comunicabilidad de la responsabilidad.

\begin{abstract}
The creation of legal entities or institutions -instrumental entities of the government administration - to implement a change in the system of the activities assigned to the government administration, is aimed at eluding the administrative law thereby, making the state's responsibility unviable. However, this distorts the very reason for the existence of the state's public entities, since it makes no sense to exempt the State from responsibility when the activity that causes the damage has been placed by it, in the hands of a third person who exercises it. Facing this, and considering that a society that fails to recognize that the government administration must meet the general objectives subject to the full extent of the law, "or that recognizing it, adds observations or exceptions thereto, does not truly live under a system of rule of law" (Duguit), the "communicability" of the responsibility has been proposed so that the citizen damaged by a public entity is not deprived of a fair redress.
\end{abstract}

Key words: State responsibility - Government administration - Administrative Law - Instrumental administration - Rule of Law - Communicability of the responsibility.

\footnotetext{
* Profesor de la Universidad Mayor de la República Oriental del Uruguay, Director del Instituto de Derecho Administrativo y Director del Instituto de Derecho Informático en la Facultad de Derecho de dicha universidad.
} 
Sumario:

1. Realidad y derecho. Vaivenes contemporáneos de la responsabilidad estatal a partir de la reflexión de dos administrativistas contemporáneos. 2. Enfoque desde la realidad. Desafíos que plantea la fuga del derecho administrativo. 3. Enfoque desde el derecho. 3.1. Reafirmación de la responsabilidad como principio general. 3.2. Necesaria extensión de la responsabilidad estatal. 3.3. Nuevos medios para hacer valer la responsabilidad estatal. 4. Conclusión.

\section{REALIDAD Y DERECHO}

Hace poco escribí que "La calidad del Estado de derecho depende, en buena medida, de la amplitud de la responsabilidad estatal y de la eficacia de los medios para hacerla valer en tiempo y forma"1.

Tal afirmación no parecería necesitada de demostración cuando nos aproximamos al fin de la primera década del siglo XXI ya que la tendencia del siglo pasado fue precisamente la de extender progresivamente el campo de la responsabilidad estatal como manifestación esencial del Estado de derecho.

Sin embargo, como bien lo ha puesto de manifiesto Agustín Gordillo², "En el tema de la responsabilidad del Estado se ha producido un doble fenómeno bastante curioso. Al mismo tiempo que disminuye la responsabilidad interna del Estado (contrariando la evolución histórica que ha sido siempre creciente hacia la responsabilidad del Estado), aumenta la responsabilidad internacional. Ello es contradictorio: no es coherente que en un ámbito la responsabilidad vaya en constante aumento y en el otro en constante disminución".

En efecto, mientras que en el plano interno se asiste a la caída del paradigma de que el Estado es eternamente solvente y, por ende, siempre puede responder, en el ámbito internacional el Estado es exigido de nuevas maneras y con consecuencias hasta insospechables, por violación de los derechos humanos, por los compromisos asumidos en materia de protección de inversiones extranjeras, por las obligaciones derivadas de los contratos de crédito externo o por el simple hecho del sometimiento a jurisdicciones extranacionales, sean judiciales o arbitrales.

Paralelamente, la actuación estatal a través de terceros - sean entidades privadas o públicas no estatales - o acudiendo al derecho privado ha generado una sensación de retorno a una cierta irresponsabilidad pública. Frente a tal realidad, es necesario coincidir con reciente afirmación de Eduardo Soto 
Kloss ${ }^{3}$, quien ha enfatizado que "sin responsabilidad no hay derecho que merezca ese nombre y sin responsabilidad del Estado no hay Estado de derecho que pueda existir. Y es que la existencia real de la responsabilidad del Estado, y especialmente por los daños que produzca su actividad o inactividad administrativa, es el índice más efectivo para saber si un determinado país es un Estado de derecho o simplemente allí el derecho es, en último término, una farsa".

A la luz de los fenómenos apuntados, se impone examinar el hoy de la responsabilidad estatal partiendo del análisis de la realidad.

\section{ENFOQUE DESDE LA REALIDAD}

Lo que nos muestra la realidad es que las administraciones institucionales de nuestros días procuran migrar hacia el derecho común ${ }^{4}$, lo que concretan de dos maneras ${ }^{5}$ : mediante el recurso por parte de la administración pública en su actuación al ordenamiento jurídico privado y a través de la constitución de formas organizativas de derecho privado.

Desde el punto de vista regulatorio, se trata de un planteo no solo contradictorio sino sorprendente ${ }^{6}$ ya que lo propio de la actividad pública, regida por el principio de especialidad, no se corresponde con el derecho regulador de la actividad privada, presidido por el principio de libertad". "Hay que subrayar que es la legalidad - se ha dicho - y no la libertad lo que está en la base misma de la actuación de los poderes públicos, y que ello no es un prurito de los juristas, como alguien podría creer, sino una exigencia indeclinable del principio democrático mismo" 8 .

Es que el derecho público está lleno de "privilegios en más" pero también de "privilegios en menos" 9 ya que junto a un amplio contenido de régimen exorbitante - plasmado en prerrogativas de la administración, tales como la presunción de legitimidad de los actos administrativos, la ejecutoriedad, la actuación coactiva, el régimen procesal privilegiado, y la inembargabilidad de sus bienes - impone a la administración restricciones en su obrar a través de una actuación formalizada y uniformizada, sometida a controles y publicidad, con fines de garantía que no justifican su avasallamiento en aras de la sola eficiencia ${ }^{10}$.

En rigor, como gráficamente se ha expresado, se actúa bajo "el mito de la eficacia como pretexto y la exoneración de controles como objetivo"11. 
Por eso, bien se ha dicho que "la supuesta huida al derecho privado no es, en realidad, sino una huida del derecho"12 ya que "se trata de escapar de todo un ordenamiento, en concreto, huir de la legislación de contratos del Estado, del ordenamiento jurídico en materia de selección, promoción y control del personal, y enajenación de bienes"13.

Desde el punto de vista organizativo, se ha sostenido que la buena marcha de determinadas actividades estatales - especialmente, las de carácter económico- requiere de unas organizaciones con cierta autonomía, que se rijan por criterios de tipo empresarial y que se responsabilicen directamente de los resultados de su actividad, de modo de neutralizar el sobredimensionamiento de algunas estructuras estatales, el descrédito de lo estatal y su escasa eficacia.

Consecuentemente, "asistimos en los últimos años a un fenómeno de creación de entes instrumentales encargados de la gestión de amplios sectores de la actividad de la administración que prescinden en su actuación de normas del derecho administrativo. Esta llamada huida del derecho administrativo ha supuesto la utilización instrumental del derecho privado en las relaciones de tales entes con terceros e, incluso, en su propia organización y estructura. En síntesis, con invocación del principio constitucional de eficacia se trata de excluir los procedimientos de control del gasto y de la selección de contratistas y de funcionarios. Si bien debe tenerse en cuenta que la noción de eficacia no es la misma cuando se trata de la gestión pública que cuando se trata de actividad privada. La administración no es una mera organización lucrativa como son las organizaciones empresariales privadas"14.

En dicho marco, son conocidos como entes instrumentales de la administración aquellas personas jurídicas constituidas o creadas por una administración pública, dotadas de personalidad jurídica propia, y a las que se encomienda la gestión de alguna o algunas de las competencias de titularidades del ente matriz"15.

Así, suelehablarse de "administración instrumental" para referirseal "conjunto de personas jurídicas que una administración pública como competencias propias crea, para la mejor consecución de sus fines y sobre la que ejerce una posición superior de dependencia"16.

Por lo tanto, dos son las notas esenciales que caracterizan a este fenómeno de "instrumentalización", a saber: 
a) La personalidad jurídica propia de los entes instrumentales; $y$

b) Su relación de instrumentalidad o dependencia con la administración que los crea y a cuyos fines sirven.

Por lo que refiere al primer aspecto, la "nota común en todos estos casos es que la instrumentalización se consigue a través de la fórmula de la concesión de personalidad jurídica"17. La personalidad jurídica distinta formalmente de la del Estado es el eje sobre el que gira la construcción de los entes instrumentales $^{18}$ y constituye, por ende, el criterio básico para identificar la naturaleza de esa variedad de entes ${ }^{19}$.

Precisamente, "es la utilización del concepto de persona jurídica lo que permite a estos organismos y, paradójicamente, al propio Estado, puesto que estos organismos son parte constitutiva del Estado, huir del derecho administrativo del Estado" 20 .

En cuanto al segundo aspecto, los entes instrumentales se caracterizan por servir a una administración pública que los crea para que cumplan con un fin o servicio propio de esta, sometidos a su dirección y control.

Por ende, se trata de diferentes personas jurídicas, pero que sirven instrumentalmente a un mismo interés, que no puede ser otro que el interés general de la administración ${ }^{21}$. La personalidad jurídica de los entes instrumentales los convierte en centros de imputación de situaciones y relaciones jurídicas, pero esto no evita que el ente y el órgano estatal del cual depende constituyan un "complejo orgánico unitario". La relación de dependencia con respecto al órgano estatal es entonces, y precisamente por esto, muy estrecha.

Por ende, las entidades instrumentales tanto pueden ser personas jurídicas públicas como privadas, y tanto pueden ser sociedades como no serlo. "De lo único que se puede estar seguro es, precisamente, de que son estatales. Es decir, esta es su única realidad por encima de todos los camuflajes y formalismos"22.

Al respecto, antes de ahora, partiendo de que la distinción entre personas estatales y no estatales está dada por su pertenencia o no a la organización jurídica de la colectividad (o sea, al Estado en sentido amplio por oposición al Estado en sentido estricto, entendido como persona pública mayor ${ }^{23}$, he sostenido que la estatalidad de las empresas reguladas por el derecho privado pero en las que participa alguna entidad estatal, está dada precisamente por esa pertenencia - total o parcial, cualquiera sea su proporción - a la colectividad organizada ${ }^{24}$. Por lo tanto, si bien se coincide en que el carácter estatal 
o no estatal viene dado por el capital o patrimonio, no se comparte la apreciación de que la persona jurídica privada será estatal solo cuando su patrimonio pertenezca mayoritaria o íntegramente a una entidad estatal, en tanto que no lo será cuando esa participación sea minoritaria ${ }^{25}$ ya que la sola presencia del Estado (en sentido amplio) califica en todos los casos a la institución de que se trate, cualquiera sea el quantum de su aporte.

Los problemas jurídicos derivados de la generación de entidades de derecho privado para vehiculizar un cambio de régimen de las actividades asignadas a administraciones públicas son múltiples y diversos, destacándose la inviabilidad de interponer recursos administrativos contra sus actos, la inaplicabilidad de las normas relativas a la contratación administrativa y la ausencia de control presupuestal, entre otros ${ }^{26}$.

\section{ENFOQUE DESDE EL DERECHO}

Para examinar en perspectiva jurídica el impacto que plantea sobre la responsabilidad estatal la apuntada realidad de huída del derecho administrativo ${ }^{27}$, el punto de partida no puede ser otro que la constatación de que "la responsabilidad hace al ser de los entes públicos estatales y, con ello, a su razón de ser" 28 .

\subsection{Reafirmación de la responsabilidad como principio general}

Siendo así, se impone reafirmar que la responsabilidad etática como principio general de derecho está impuesta por el hecho de que el Estado y todos sus órganos, funciones, cometidos y medios (materiales y humanos) están al servicio de la persona humana y sus derechos fundamentales, teniendo por finalidad la consecución del bien común. En consecuencia, cualquier ámbito de irresponsabilidad, por más pequeño y excepcional que sea, violenta el Estado de derecho, implica una desigualdad y genera un agravio, que debe siempre ser reparado total e integralmente. Todo daño, cualquiera sea el órgano estatal que lo haya provocado, significa un detrimento de la esfera jurídica de alguien, es decir, un menoscabo de lo que le pertenece, una lesión en lo suyo, que debe ser reparada a quien la ha sufrido por aquel que la ha causado ${ }^{29}$.

En orden a la caracterización de los principios generales de derecho, aunque pueda parecer una simplificación o un juego de palabras, antes de ahora he propuesto hacer coincidir la definición de los mismos con su designación, a través de las tres palabras que componen su nombre ${ }^{30}$.

En primer lugar, son principios por cuanto constituyen los soportes primarios estructurales del sistema jurídico todo, al que prestan su contenido. Ello es así 
porque "en todo sistema jurídico hay cantidad de reglas de gran generalidad, verdaderamente fundamentales, en el sentido de que a ellas pueden vincularse, de un modo directo o indirecto, una serie de soluciones expresas del derecho positivo a la vez que pueden resolverse, mediante su aplicación, casos no previstos, que dichas normas regulan implícitamente" ${ }^{\prime \prime}$.

La propia designación de "principios" alude a lo primero, o sea, lo que antecede plenamente a cuanto le sigue. Por eso, "Háblase de principios habitualmente para referirse a aquellos primeros criterios o fundamentos que expresan el asiento - piedras sillares - de un ordenamiento (jurídico, en la especie que nos ocupa). Criterios de verdad que se procura hallar. Su noción de base alude entonces, a un sentido no solo ontológico sino también lógico, en cuanto atendemos con ellos a unos soportes primarios estructurales del sistema entero del ordenamiento jurídico, al que prestan todo su sentido" ${ }^{32}$.

En efecto, "Cuando se habla de principio, lo primero que viene a la mente es la idea de inicio, de comienzo, de lo que se parte, y que se refiere a una acción, a una actividad, a un procedimiento o iter o camino, que se desarrolla y lleva a un término, a un fin. La idea de principio lleva en sí la de aquello que origina, que es origen o fuente de algo"33.

En segundo lugar, son reglas de carácter general porque trascienden un precepto concreto y no se confunden con apreciaciones singulares o particulares.

En rigor, lo general seoponea lo particular, demodo queno equivale a vaguedad sino que resulta abarcativo en su supuesto de la categoría o clase de sujetos abstractamente comprendidos sin individualizarlos. Es más: en la medida que refieren a las verdades supremas del derecho, resultan virtualmente comunes a todos los sistemas ya que la afirmación de que los principios generales son válidos solamente para un sistema, es una contradicción con su ratio juris de carácter universal que, desde los romanos, ha sido patrimonio común de nuestra conciencia jurídica ${ }^{34}$.

En tercer lugar, los principios generales son de derecho ya que se trata de fórmulas técnicas del mundo jurídico y no de simples criterios morales, buenas intenciones o vagas directivas. A pesar de que no se presentan habitualmente con la estructura típica de una regla de derecho, ninguna duda puede existir acerca de que revisten el carácter de tal ${ }^{35}$.

Siendo así, constituyen fuente directa y principal de derecho porque "sería ontológicamente absurdo y lógicamente contradictorio que siendo principios ge- 
nerales solo se apliquen si no hay texto, sino que los textos deben estar de acuerdo a los principios y los principios de acuerdo a la naturaleza de las cosas" ${ }^{\prime \prime}$.

Por eso, con carácter general, si en todos los campos del derecho la importancia de los principios generales de derecho es cardinal, ello es especialmente cierto en el ámbito del derecho administrativo, donde solo un esqueleto firme de principios permite orientarse en medio de innumerables normas sometidas a un proceso de cambio incesante. Además, son los principios generales de derecho el principal antídoto frente a la normación burocrática y son también la garantía de permanencia frente a las modas que ocasionalmente se suscitan al influjo de ideologías o tendencias políticas de momento ${ }^{37}$.

Específicamente, la obligación de responder (en el más amplio sentido) es un principio general de derecho - regla de derecho que hace parte del haz de la juridicidad constitutivo del bloque de la legalidad - conforme al cual todo órgano del Estado debe restituir lo suyo a cada quien cuando le ocasione un daño que la víctima no estaba obligada a soportar y que, por ende, no solo le ocasiona un menoscabo sino que implica una desigualdad ante las cargas públicas.

Con base en la afirmación de la responsabilidad estatal como principio general de derecho, es misión del derecho administrativo bregar para hacer verdad la responsabilidad etática en todos los planos ya que, como enseña Eduardo Soto Kloss ${ }^{38}$, lo he destacado antes ${ }^{39}$ y lo recalca Celso Antonio Bandeira de Mello ${ }^{40}$, quien dice derecho, dice responsabilidad.

En su mérito, no pueden existir sujetos irresponsables ni reductos de irresponsabilidad, de modo que el Estado debe responder siempre, cualquiera sea la función jurídica de que se trate, la causa motivante, la índole de la actividad y el tipo de intervención de que se trate ${ }^{41}$.

En primer lugar, la generalidad de la responsabilidad estatal conduce a afirmar que el Estado debe responder por todas sus funciones, comprendiendo no solo la actividad que despliega en ejercicio de la función administrativa sino también la legislativa, la jurisdiccional y la constituyente.

En segundo lugar, el Estado debe responder por toda causa, es decir, no únicamente por sus acciones sino también por sus omisiones o inactividad.

En tercer lugar, el Estado debe responder por su obrar de cualquier naturaleza, tanto ilícito como también lícito ya que la antijuridicidad no es a su respecto la única fuente de responsabilidad. 
En cuarto lugar, el Estado debe responder por su actuación directa e indirecta, o sea, por la propia y por la de los terceros que participan en el desenvolvimiento de sus cometidos.

\subsection{Necesaria extensión de la responsabilidad estatal}

El último de los aspectos referidos nos pone en el camino de examinar la responsabilidad estatal en los casos de huída del derecho administrativo ya que no tendría sentido eximir de responsabilidad al Estado cuando la actividad prestacional que causa el daño ha sido puesta por él en manos del tercero que la ejerce ${ }^{42}$.

Precisamente, frente a la apuntada realidad de acudir a intermediarios preexistentes o creados al efecto con el propósito de soslayar controles y eludir procedimientos de garantía, se ha postulado la "comunicabilidad" de la responsabilidad, de modo que el ciudadano lesionado por un ente instrumental no se vea privado de la justa reparación por parte de la Administración que es titular del servicio de que se trate ${ }^{43}$.

En materia de concesiones, ya he sostenido antes de ahora que el servicio concedido sigue siendo de la administración concedente, por lo que esta "no puede desinteresarse de él en tanto este sigue siendo un cometido de ella" 44 . Esto es así porque las actividades cuya ejecución la ley autoriza a la administración a contratar con particulares, siguen siendo actividades del Estado; lo que cambia es el medio a través del cual se ejecutan, pero siguen siendo cometidos estatales ${ }^{45}$.

En efecto, la transferencia de la prestación de un cometido estatal a uno o más particulares, genera un entramado de relaciones jurídicas diversas, propias de lo que se ha llamado el "triángulo Administración-gestor-usuario" 46. Cuando esa transferencia refiere a la ejecución del cometido y no a su titularidad, cabe examinar por separado, por sus proyecciones sobre las responsabilidades involucradas, las que se traban entre el prestatario del cometido y los terceros (especialmente los usuarios del mismo), entre la administración concedente y dicho prestatario, y entre los particulares y la administración titular del cometido de que se trate.

Este tercer tipo de relaciones enfrenta a la cuestión de si la administración puede ser llamada a responsabilidad por los particulares en virtud del daño ocasionado por el concesionario del servicio público o prestatario del servicio de que se trate. 
Sobre el particular, nuestra doctrina administrativista tradicional afirmó que la responsabilidad de la administración no se extiende a los actos o los hechos de los concesionarios de servicios públicos o de sus empleados porque, si bien el Estado ejerce sobre los concesionarios poderes de vigilancia y contralor, no tiene ni la gestión ni la dirección del servicio, a lo sumo determina con carácter general, lo que no presupone dirección, las reglas de actuación a que deberá ajustarse el mismo ${ }^{47}$.

Sin embargo, a la luz de los modernos procesos de transferencia a particulares de actividades propias de las entidades estatales, es razonable pensar que "va a poder sostenerse con buen fundamento que el Estado también será responsable de los daños que se causan en la ejecución de esos servicios que no están confiados a su gestión pero sí bajo su dirección" 48 ya que el artículo $24^{\circ}$ de la Constitución proclama que todas las entidades y órganos estatales "serán civilmente responsables del daño causado a terceros en la ejecución de los servicios públicos confiados a su gestión o dirección".

Analizandoesta disposición, el máximo comentarista denuestra Carta afirmaba décadas atrás que la misma "trata de los daños que se causen a terceros en la ejecución de los servicios públicos confiados a la gestión o dirección de las personas públicas. Este distingo entre gestión o dirección de las personas públicas, podría también hacer suponer que el caso del daño causado por empresas concesionarias o por empleados de empresas concesionarias está comprendido en el régimen de responsabilidad" 49 .

Lo antedicho resulta corroborado si se subraya el rol de la administración concedente como garante del servicio de que se trate ${ }^{50}$, en cuyo caso su consecuente responsabilidad es inexcusable. Carecería de sentido que la administración respondiese de su propia actividad cuando la realiza directamente y, en cambio, no lo hiciere cuando actúa a través de un concesionario ${ }^{51}$.

Frente a otras tercerizaciones, es decir, cuando la administración se vale de un sujeto instrumental, el razonamiento no puede ser distinto. No es posible concluir que la administración puede irresponsabilizarse a sí misma mediante el cómodo arbitrio de acudir a colaboradores o sustitutos, ya que nadie - tampoco la administración - puede conseguir eludir la responsabilidad que le incumbe o desprenderse de la responsabilidad que se deriva de sus propios actos $\mathrm{u}$ omisiones ${ }^{52}$.

En particular, las dos notas típicas de los entes instrumentales antes referidas - personificación e instrumentalidad - abonan dicha solución de principio, determinando la "comunicabilidad" de la responsabilidad. 
En cuanto al primer aspecto, parece evidente que el aprovechamiento de la personalidad jurídica propia del ente instrumental no puede liberar a la administración matriz de su calidad de responsable por el buen desempeño de los cometidos que le han sido confiados, lo que abona tal comunicabilidad.

Así lo ha entendido, por ejemplo, el Tribunal Supremo español, afirmando con acierto que "el instrumento en que consiste la personificación jurídica puede resultar adecuado como método de organización para facilitar la eficacia en la actuación de las administraciones públicas, pero no permite a estas exonerarse de sus respectivas responsabilidades frente a los particulares cuando las personas jurídicas creadas para atender a un sector de la actividad administrativa correspondiente a la administración matriz están en relación con esta o con sus competencias, dependen de ella o se integran en su órbita de actuación" 53 .

Es que cuando se trata de entidades estatales, "la mera utilización instrumental de formas privadas de personificación en absoluto puede justificar la minoración de las garantías del ciudadano" ${ }^{24}$. Justamente es misión del Estado cumplir el rol de garante de los derechos de los ciudadanos, dada su índole de ser para otros ${ }^{55}$. Ese rol servicial está en su propia naturaleza, de la cual no puede abdicar ${ }^{56}$.

Con relación al segundo aspecto, la unidad organizativa que componen el ente matriz y el instrumental también determina la necesaria comunicabilidad de la responsabilidad ya que la instrumentalidad no puede conspirar contra el interés general sino que debe servirlo.

Según se ha destacado, "La consecuencia de esta aproximación es la responsabilidad y la posibilidad de principio de control de la actividad de esos entes, salvando el dato formal de la personalidad jurídica, cualquiera que sea el derecho a que aquella se someta, porque son administración que sirve con eficacia los intereses generales con sometimiento pleno al derecho, aunque no sea el tradicional derecho administrativo. La instrumentalidad comprende también el uso de estatutos que necesitan ser integrados también en el ordenamiento estatal; es la utilidad y la servidumbre de la perspectiva estatutaria de la administración y de su derecho" 57 .

$\mathrm{Al}$ crear la entidad instrumental, la administración pública matriz no se desprende de su competencia, la que es irrenunciable, no constituyendo la técnica organizativa de la instrumentalidad una vía apta para desplazar la responsabilidad política y jurídica que recae necesariamente sobre la Administración pública en cuestión ${ }^{58}$. 
Un tercer aspecto, conjuntamente con las dos notas características de los entes instrumentales, cabe adicionar para sostener que la comunicabilidad de la responsabilidad desde estos hacia su entidad matriz deriva de un postulado esencial del Estado de derecho, como es la garantía institucional de la responsabilidad estatal como regla inherente al principio general de responsabilidad.

Al amparo de la misma, "todos los particulares están garantizados en cuanto sus bienes o derechos puedan sufrir lesiones procedentes de los servicios públicos. Admitir, de plano, una diferenciación de tratamiento, si los servicios se prestan bajo formas jurídicas de Derecho privado, sería equivalente a reconocer la existencia de particulares de primera o de segunda clase, pues las garantías de quienes se sintiesen lesionados por actuaciones de entidades públicas serían, hipotéticamente, mayores" ${ }^{59}$.

Tampoco el principio de eficacia administrativa puede utilizarse para traicionar el principio y las exigencias propias de un Estado de derecho. Como bien se ha dicho, "Aparte de lo cuestionable que resulta en el plano de nuestro sistema jurídico eliminar la responsabilidad del Estado por los actos de una sociedad mercantil de su propiedad (o que administra), creemos que el Estado, en cuanto asociación perfecta o soberana, no puede guiarse en este aspecto por finalidades propias de quienes privadamente unen sus capitales para la realización de un negocio o negocios mercantiles. El Estado debe procurar siempre - aun a través de estas formas jurídicas privadas - la concreción del bien común y es evidente que este no resulta compatible con la limitación de la responsabilidad de sus entidades, cualquiera fuere su condición jurídica" 60 .

En suma, la conclusión que se impone es que "el ciudadano que se relaciona con la administración y sufre una lesión, no puede ver desatendida su petición indemnizatoria porque el daño haya sido causado por un ente instrumental de aquella. Para transmitir la responsabilidad a la administración matriz, la jurisprudencia ha acudido a considerar bien planteada la relación jurídico-procesal si se demanda o comparece en el proceso la administración matriz y no la filial; o estima la solidaridad de responsabilidad de la matriz y filial por ser aquella la titular del servicio cuya gestión se encomienda a esta; o bien, por último, acude a levantar el velo para negar virtualidad a la vestidura de la personalidad jurídica" 61 .

Sin perjuicio de la reafirmación del principio general de la responsabilidad, en cada caso habrá que acudir a los criterios de imputación que puedan corresponder para apreciar la comunicabilidad a la administración correspondiente ${ }^{62}$. 


\subsection{Nuevos medios para hacer valer la responsabilidad estatal}

Para hacer verdad en la práctica la efectiva responsabilidad estatal cuando una administración se vale de vías oblicuas para fugarse del derecho administrativo, este ha acudido a soluciones de principio, normativas y jurisprudenciales.

En primer lugar, las soluciones de principio pasan por la plena reivindicación del máximo valor y fuerza de los principios generales de derecho, entre los cuales el principio de responsabilidad aparece íntimamente asociado al principio de juridicidad, que refiere al sometimiento integral del Estado a la regla de derecho, tanto en su ser como en su obrar ${ }^{63}$.

Por eso, es preferible, por más abarcativa, su designación como principio de juridicidad y no la más usual de principio de legalidad, derivada de la expresión "bloque de la legalidad" debida a Maurice Hauriou ${ }^{64}$.

Se trata, del "principio de los principios" - al decir de Benoit Jeanneau ${ }^{65}$ - ya que, como reza el acápite del art. $2^{\circ}$ del Reglamento de procedimiento administrativo aprobado por el Decreto $\mathrm{N}^{\circ}$ 500/991 de 27 de setiembre de $1991^{66}$, “La administración pública debe servir con objetividad los intereses generales con sometimiento pleno al derecho" ${ }^{67}$. Según sentenciara León Duguit, “Una sociedad que no lo reconozca o que, reconociéndolo, le agregue reservas o excepciones, no vive verdaderamente bajo un régimen de Estado de derecho" ${ }^{\prime \prime 6}$.

Ahora bien: como se ha destacado con acierto, "la vigencia efectiva del principio de legalidad impone la existencia de un conjunto de mecanismos de control a través de los cuales pueda asegurarse eficazmente el sometimiento de la administración al sistema normativo" 69 . De lo contrario, dicho principio "quedaría en simple declaración programática"70.

Dentro de estos mecanismos, la técnica primordial de garantía ha estado y está constituida por el control jurisdiccional, respecto al cual se ha proclamado la universalidad ${ }^{71}$, de modo que "cualquier acto o conducta, positiva o negativa, de la administración y de sus agentes, puede ser sometida al enjuiciamiento por parte de órganos judiciales, a instancia de cualquier persona o entidad (pública o privada) a quienes dichos actos o conductas lesionen en sus derechos o intereses" ${ }^{\prime 2}$.

Pero de nada sirve la mera proclamación de la tutela jurisdiccional si la misma no es efectiva ${ }^{73}$. En tal sentido, el principio de la tutela jurisdiccional efectiva 
despliega sus efectos en tres momentos distintos: primero, en el acceso a la justicia; segundo, una vez en ella, que sea posible la defensa y obtener solución en un plazo razonable; y tercero, una vez dictada la sentencia, en la plena efectividad de sus pronunciamientos ${ }^{74}$.

Esa efectividad supone una vitalización del control jurisdiccional $\mathrm{y}$, consecuentemente, la previsión amplia de medidas cautelares eficaces frente a la administración y sus personeros ${ }^{75}$, así como el cumplimiento cabal de los fallos contra la administración ${ }^{76}$.

Frente al escenario de la huida del derecho administrativo, no basta con un análisis descriptivo sino que es necesario concretar sus múltiples aplicaciones ${ }^{77}$.

Desde esta perspectiva, se impone la vuelta al derecho administrativo ${ }^{78}$ o un "nuevo impulso"79 del mismo frente al "espejismo" 80 de refugiarse en el derecho privado, reivindicando que, en cualquier caso, la actuación administrativa, tanto directa como indirecta, encuentra límites infranqueables en el respeto a los derechos fundamentales y a los principios generales de legalidad, prohibición de la arbitrariedad, objetividad y neutralidad, los cuales tienen un alcance global, cualquiera sea la forma o el ropaje jurídico que se haya puesto la administración ${ }^{81}$.

Es que "la realidad nos está mostrando hasta qué punto hoy emerge con fuerza un nuevo derecho administrativo como derecho del poder para la libertad" cuya tarea de garantizar los derechos de los ciudadanos requiere de una presencia pública, mayor en intensidad que en extensión. En la medida que se abren a la libertad espacios antes dominados por monopolios, crece un nuevo derecho administrativo; en la medida que la administración procura hacer posible la libertad y la igualdad, emerge un nuevo derecho administrativo; en la medida que la autotutela administrativa se compatibiliza con la tutela judicial, aún cautelar, se desarrolla un nuevo derecho administrativo; en la medida que integración y solidaridad caracterizan el modelo de Estado moderno, se fortalece un nuevo derecho administrativo; en la medida que la acción pública esté impregnada por la promoción de los derechos fundamentales, se consolida un nuevo derecho administrativo ${ }^{82}$.

En segundo lugar, entre las soluciones normativas, son múltiples los ejemplos de extensión al fenómeno de las tercerizaciones, de las regulaciones propias del derecho administrativo a fin de abarcar las manifestaciones contractuales de la huída. 
Así ha ocurrido a nivel interno de los países más adelantados como desde fuentes supranacionales resultantes de lo que ha dado en llamarse "convergencia de los derechos administrativos" 83 impuesta por la globalización, lo que permite hablar de la formación de un "ius commune administrativum", que se encuentra en una constante relación de interacción con los derechos nacionales, en los cuales se inserta y a los cuales condiciona en influencia recíproca ${ }^{84}$.

En función de dicha realidad, los derechos administrativos nacionales se explican cada vez más desde su integración en otros sistemas jurídicos más complejos, que no responden a las reglas tradicionales de los ordenamientos jurídicos estatales ${ }^{85}$.

Una manifestación de tal fenómeno se manifiesta en el pasaje de los contratos administrativos a los contratos públicos, cuestión que no encierra solo una cuestión de nombre sino que traduce los esfuerzos realizados desde la Organización Mundial del Comercio, la Unión Europea, el Mercosur y muchos países para, a través de la noción de "poderes adjudicadores" 86 , introducir un concepto eminentemente funcional (y ya no orgánico) de quienes quedan alcanzados por la normativa respectiva, que ya no son solo las administraciones públicas sino también otras entidades del sector público no estatal o privadas creadas para satisfacer necesidades de interés general.

En efecto, frente al abuso de las técnicas jurídicas privadas por las administraciones públicas, debe estarse al dato de la "influencia dominante" del poder público sobre el ente adjudicador y la índole de la actividad de que se trate ya que, cuando se atienda a la satisfacción de necesidades de interés general, los contratos respectivos deberán sujetarse a los procedimientos y controles generales. Ello debe ser así porque la búsqueda de la eficacia (entendida desde una perspectiva económica y no social) en ningún caso puede legitimar la transgresión de previsiones normativas so pretexto de que estas imponen trámites formales cuya observancia es larga o costosa para resolver la cuestión de que se trate ${ }^{87}$.

De este modo, la nueva normativa sobre contratos del sector público adopta un criterio funcional para el tratamiento de la materia, que ya no pivota - como antes - sobre sujetos, sino sobre las diferentes fases del contrato: preparación, selección del contratista, adjudicación, efectos, cumplimiento y extinción ${ }^{88}$.

En tercer lugar, las soluciones jurisprudenciales han intentado acortar la distancia entre "verdad material" y "verdad formal" a propósito 
de la interposición por la administración de terceros personificados, mediante la técnica del levantamiento del velo y su prolongación, el "desenmascaramiento", expresión que se ha usado por algunos autores por la identificación etimológica entre la "máscara" usada por los actores en el teatro antiguo, y la "personificación" como instrumento para "enmascarar" la realidad ${ }^{89}$.

Dicha técnica del levantamiento del velo tiene origen pretoriano norteamericano bajo la denominación de "to disregard the legal entity" o "to pierce the corporate veil", es decir, allanar la personalidad jurídica o descorrer el velo de la personalidad jurídica, con lo cual se alude al objetivo final del instituto ${ }^{90}$.

Su llegada al campo del derecho público se produce como consecuencia de la proliferación de entidades instrumentales a través de las cuales las administraciones eluden las normas sobre contratación pública e intentan soslayar el régimen jurídico que les es propio ${ }^{91}$.

Se trata de propiciar "una visión estrictamente funcional de una realidad múltiple que debe ser entendida como un complejo organizativo, y con ello propugnamos superar la mera formalidad jurídica que califica a cada entidad instrumental como una persona jurídica reconocida por el ordenamiento jurídico con capacidad de configurar una voluntad propia oponible erga omnes, incluyendo en esa total autonomía volitiva su relación con la matriz"92.

En tal sentido, en Europa, el derecho comunitario ha propiciado "una definición realista de lo que ha de entenderse por poder público a los efectos de asegurar el máximo efecto útil de sus disposiciones que demandan una aplicación uniforme en todos los Estados, no condicionada por el ejercicio de las potestades organizatorias. De esta forma, la jurisprudencia comunitaria, en sectores como las ayudas estatales o la apertura de la contratación pública, no ha mostrado ningún pudor a la hora de levantar el velo de las personificaciones interpuestas, consagrando una noción eminentemente funcionalista del poder público" ${ }^{\prime 93}$.

Es lógico que así sea, ya que la administración no puede irresponsabilizarse a través del sencillo expediente de "enmascarar" su quehacer mediante el uso de figuras asociativas, comerciales o de otro tipo, que se crean o interponen en el tráfico jurídico sin perder su carácter de alter ego de la matriz ${ }^{94}$. 


\section{CONCLUSION}

A modo de conclusión, frente a la realidad fugitiva, desde el derecho se impone la reafirmación del principio general de la responsabilidad estatal, en íntima interrelación con los principios de juridicidad y tutela jurisdiccional efectiva, que son sustento del Estado de derecho democrático y social del nuevo siglo y que abogan con sólido fundamento por el retorno al derecho administrativo.

No puede ser de otra manera si se tiene en cuenta la centralidad de la persona ante la existencia misma de las administraciones y de su consiguiente obrar, el cual debe estar presidido por la servicialidad, sea que la misma se manifieste $\mathrm{y}$ brinde directa o indirectamente.

El fundamento de esta centralidad - que explica el carácter vicarial de la administración - no es otro que la eminente dignidad humana ${ }^{95}$.

Como bien se ha enseñando, "Es incuestionable que cualquiera que sea la finalidad perseguida por la administración, cualquiera que sea la forma de actuación y cualquiera que sea la realidad social sobre que recaiga, ha de respetar como algo sagrado e inviolable la dignidad de la persona. Y algo más, todos y cada uno de sus actos han de estar informados por este valor esencial" ${ }^{\prime 96}$.

1 Delpiazzo, Carlos E. Estudios sobre la Responsabilidad de la Administración. Montevideo: U.M., 2009, p. 10.

2 Gordillo, Agustín. «Responsabilidad del Estado en el Derecho internacional». En: Jornadas sobre responsabilidad del Estado y del funcionario público. Buenos Aires: Edit. Ciencias de la Administración - Universidad Austral, 2001, pp. 361 y sgtes.

3 Soto Kloss, Eduardo. «Responsabilidad del Estado por daños de su Administración. Algunos casos de jurisprudencia ( $2^{\circ}$ semestre de 2008)». Rev. Ius Publicum. Santiago de Chile, 2009, N²2, p. 92.

4 Delpiazzo, Carlos E. «Actividad administrativa y Derecho privado». Rev. de Derecho de la Universidad de Montevideo. Montevideo, 2002, Año I. N 1, pp. 25 y sgtes.; y «Pasado, presente y futuro del Derecho Administrativo». Rev. Argentina del Régimen de la Administración Pública. Buenos Aires, 2007, Año XXIX. N 348, pp. 243 y sgtes.

5 Troncoso Reigada, Antonio. Privatización, empresa pública y Constitución. Madrid: Marcial Pons, 1997, p. 29.

6 Muñoz, Guillermo Andrés. «Derecho público y Derecho privado en la organización de la Administración». En: Muñoz, Guillermo Andrés y Grecco, Carlos Manuel. Fragmentos y testimonios del derecho administrativo. Buenos Aires: Ad-Hoc, 1999, p. 459.

7 Delpiazzo, Carlos E. «Los derechos fundamentales y la libertad económica». En: VII Jornadas Internacionales de Derecho Administrativo. Caracas: FUNEDA, 2004, pp. 66-67.

8 Garcia de Enterría, Eduardo y Fernández, Tomás Ramón. Curso de Derecho Administrativo. T. I. 12ª edición, Madrid: Civitas, 2004, pp. 410-411.

9 Parejo Alfonso, Luciano y otros. Manual de Derecho Administrativo. Vol. I. 4 edición, Barcelona: Ariel, 1996, pp. 341 y sgtes.

10 Delpiazzo, Carlos E. Actividad administrativa y ..., p. 26.

11 Martin Retortillo, Sebastián. «Reflexiones sobre la huida del Derecho Administrativo». Rev. de Administración Pública. Nº 140, Madrid, 1996, p. 36. 
12 Sala Arquer, José Manuel. «Huida al Derecho privado y huida del Derecho». Rev. Española de Derecho Administrativo. N $^{\circ}$ 75. Madrid: Civitas, 1992, p. 399.

${ }^{13}$ Villar Palasí, José Luis. «Tipología y Derecho estatutario de las entidades instrumentales de las Administraciones públicas». En: AA.VV. Administración instrumental. Homenaje al Profesor Manuel Francisco Clavero Arévalo. T. I. Madrid: Civitas, 1994, pp. 164-165.

14 Fernández Montalvo, Rafael. «Régimen de contratación de la administración instrumental». En: AA.VV. La Administración Instrumental. VIII Jornadas del Gabinete Jurídico de la Junta de Andalucía. Sevilla, 2005, pp. 123-124.

15 Ballesteros Fernández, Ángel. «La responsabilidad patrimonial de los entes instrumentales de la Administración y su transmisión a la entidad matriz». Rev. de Estudios de la Administración Local y Autonómica. $\mathrm{N}^{\circ}$ 300-301. Madrid, 2006, p. 565.

16 Ortiz Mallol, José. «La relación entre la entidad matriz y la instrumental: algunas notas». En: AA.VV. La Administración Instrumental. VIII Jornadas del Gabinete Jurídico de la Junta de Andalucía. Sevilla, 2005, p. 192.

17 Garrido Falla, Fernando. «Origen y evolución de las entidades instrumentales de las Administraciones Públicas». En: AA.VV. Administración Instrumental. Homenaje al Profesor Manuel Francisco Clavero Arévalo. T. I. Madrid: Civitas, 1994, p. 29.

18 Morillo-Velarde Pérez, José Ignacio. «La huída del Derecho administrativo, la personalidad jurídica de las administraciones públicas y el principio de eficacia. Reflexiones». En: AA.VV. Administración Instrumental. Homenaje al Profesor Manuel Francisco Clavero Arévalo. T. I. Madrid: Civitas, 1994, p. 1006.

19 Meilan Gil, José Luis. «La funcionalidad de los entes instrumentales como categoría jurídica». En: AA.VV. Administración Instrumental. Homenaje al Profesor Manuel Francisco Clavero Arévalo. T. II. Madrid: Civitas, 1994, p. 975.

20 Garrido Falla, Fernando. Origen y evolución de ..., p. 39.

${ }^{21}$ Meilan Gil, José Luis. La funcionalidad de los entes ..., p. 988.

${ }^{22}$ Morillo-Velarde Pérez, José Ignacio. La huída del derecho administrativo, la personalidad ..., p. 1009.

${ }^{23}$ Delpiazzo, Carlos E. Derecho Administrativo Uruguayo. México: Porrúa - UNAM, 2005, pp. 123 y sgtes., y Derecho Administrativo Especial. Vol. I, Montevideo: A.M.F., 2009. Segunda edición actualizada y ampliada. pp. 165 y sgtes.

24 Delpiazzo, Carlos E. «Actividad empresaria del Estado». Rev. Uruguaya de Derecho Constitucional y Político. Tomo VII. N 39. Montevideo, 1999, p. 229; y Brito, Mariano R. y Delpiazzo, Carlos E. Derecho Administrativo de la Regulación Económica. Montevideo: U.M., 1998, p. 60.

25 Dromi, José Roberto. Derecho Administrativo Económico T. I. Buenos Aires: Astrea, 1977, pp. 36 -37.

${ }^{26}$ Echevarria Petit, José Luis. «Actuación del Estado a través de personas de Derecho privado: la huída del Derecho público». Rev. de Derecho y Tribunales. № 5. Montevideo, 2007, pp. 121 y sgtes.

27 Delpiazzo, Carlos E. Estudios sobre la Responsabilidad ..., pp. 71 y sgtes.

${ }_{28}$ Mariano R. Brito. «Responsabilidad extracontractual del Estado administrativa, legislativa y jurisdiccional». En: Estudios Jurídicos en memoria de Alberto Ramón Real. Montevideo: F.C.U., 1996, p. 130.

${ }^{29}$ Delpiazzo, Carlos E. «Responsabilidad de la Administración en Uruguay». Rev. Iberoamericana de Administración Pública. $\mathrm{N}^{\circ}$ 10. Madrid: INAP, 2003, pp. 31 y sgtes.; «Enfoque actual de la responsabilidad administrativa». En: Estudios en homenaje a don Jorge Fernández Ruiz. México: UNAM, 2005. Volumen sobre Responsabilidad, Contratos y Servicios Públicos, pp. 227 y sgtes.; y «Responsabilidad del Estado y tutela jurisdiccional efectiva». En: Estudios Jurídicos en homenaje a Mariano R. Brito. Montevideo: F.C.U., 2008, pp. 972 y sgtes.

30 Delpiazzo, Carlos E. Derecho Administrativo Uruguayo. México: UNAM - Porrúa, 2005, pp. 12 y 13.

31 Real, Alberto Ramón. Los principios generales de Derecho en la Constitución uruguaya. Montevideo, 1965, p. 16, y En: AA.VV. Los principios generales de Derecho en el Derecho uruguayo y comparado. Montevideo: F.C.U., 2001, pp. 87 y sgtes.

32 Brito, Mariano R. Derecho Administrativo. Su permanencia, contemporaneidad, prospectiva. Montevideo: U.M., 2004, pp. 37 y sgtes.

33 Soto Kloss, Eduardo. Derecho Administrativo. T. II. Santiago: Editorial Jurídica de Chile, 1996, p. 20.

34 Del Vecchio, Giorgio. Los principios generales del Derecho. Barcelona: Bosch, 1979, p. 49.

35 Cajarville Peluffo, Juan Pablo. «Reflexiones sobre los principios generales de Derecho en la Constitución uruguaya». En: Estudios Jurídicos en memoria de Alberto Ramón Real. Montevideo: F.C.U., 1996, pp. 173 y sgtes., y en AA.VV. Los principios generales de ..., pp. 137 y sgtes.

36 Barbe Pérez, Héctor. «Los principios generales de Derecho como fuente de Derecho administrativo en el Derecho positivo uruguayo». En: Estudios Jurídicos en memoria de Juan José Amézaga. Montevideo, 1958, pp. 37 y sgtes., y En: AA.VV. Los principios generales ..., pp. 19 y sgtes. 
37 Delpiazzo, Carlos E. «Eficacia aplicativa de los principios generales de Derecho en la contratación administrativa». Anuario de Derecho Administrativo. T. XIII, pp. 65 y sgtes.

38 Soto Kloss, Eduardo. Derecho Administrativo ..., pp. 285 y sgtes.

39 Delpiazzo, Carlos E. «La responsabilidad en el Derecho Público uruguayo». Rev. de Derecho. $\mathrm{N}^{\circ} 3$. Montevideo: Publicación arbitrada de la Universidad Católica del Uruguay, 2008, pp. 59 y sgtes.; «Acerca de la imputación de la responsabilidad del Estado en el Derecho comparado actual». Suplemento de Derecho Administrativo de Rev. El Derecho. Año XXXVIII, N 9975, Buenos Aires, 30 de marzo de 2000, pp. 17 y sgtes.; y «Responsabilidad del Estado para con los ciudadanos de América Latina». En: Rev. de Direito Administrativo e Constitucional. $\mathrm{N}^{\circ} 28$. Curitiba, 2007.

40 Bandeira De Mello, Celso Antonio. Curso de Derecho Administrativo. México: Porrúa - UNAM, 2006, p. 851.

${ }^{41}$ Delpiazzo, Carlos E. «Responsabilidad del Estado y tutela jurisdiccional efectiva...» pp. 974 y sgtes., y «La responsabilidad en el Derecho Público uruguayo...», pp. 67 y sgtes.

42 Bandeira De Mello, Celso Antonio. Curso de Derecho Administrativo..., pp. 671 y sgtes.

43 Ballesteros Fernández, Angel. La responsabilidad patrimonial de los entes instrumentales de la Administración y su transmisión a la entidad matriz..., pp. 570 y sgtes.

44 Delpiazzo, Carlos E. Manual de Contratación Administrativa. T. II. Montevideo, 1993, p. 88; y Contratación Administrativa. Montevideo: U.M., 1999, reedición 2004, p. 404.

45 Cajarville Peluffo, Juan Pablo. Sobre reforma del Estado y Derecho Administrativo. Montevideo: Edit. Universidad, 1996, p. 18.

46 De La Cuetara, Juan Miguel. «Tres postulados para el nuevo marco jurídico de los servicios públicos». En: AA.VV. El nuevo servicio público. Madrid: Marcial Pons, 1997, p. 134.

47 Sayagues Laso, Enrique. Tratado de Derecho Administrativo. Montevideo, 1963, Tomo I. p. 660; y Martins, Daniel Hugo. «La responsabilidad de la Administración y de los funcionarios en la Constitución uruguaya». Rev. de Derecho Público y Privado. T. 30, p. 282.

48 Cajarville Peluffo, Juan Pablo. Sobre reforma del Estado y Derecho Administrativo..., p. 22.

49 Jiménez De Arechaga, Justino. La Constitución del Uruguay de 1952. T. II. Montevideo: C.E.D., 1966, p. 315.

${ }^{50}$ De La Cuetara, Juan Miguel. «Tres postulados para el nuevo marco jurídico de los servicios públicos...», pp. 158 y sgtes.

51 Morell Ocaña, Luis. Curso de Derecho Administrativo. T. II. Pamplona: Aranzadi, p. 407.

52 González Varas Ibañez, Santiago. «La responsabilidad administrativa en casos de colaboración de los particulares en el ejercicio de funciones administrativas». Rev. Española de Derecho Administrativo. $\mathrm{N}^{\circ} 123$. Madrid: Civitas, 2004, p. 410.

53 Así: sentencia del Tribunal Supremo español de 25 de octubre de 1996. En igual sentido: sentencias de 4 de junio de 1992 y de 25 de octubre de 1996.

54 García de Enterría, Eduardo y Fernández, Tomás Ramón. Curso de Derecho Administrativo. T. II. 9a edición, p. 391.

55 Brito, Mariano R. «Planificación y libertad en el Estado social de Derecho». Rev. Uruguaya de Estudios Administrativos. Año I, Nº 1 . Montevideo, 1977. pp. 35, 40 y sgtes.

${ }^{56}$ Brito, Mariano R. «Principio de legalidad e interés público en el Derecho positivo uruguayo». Rev. La Justicia Uruguaya. T. XC, sección Doctrina, pp. 11 y sgtes.

57 Meilan Gil, José Luis. La funcionalidad de los entes instrumentales como categoría jurídica..., T. II, p. 988.

58 Ortiz Mallol, José. La relación entre la entidad matriz y la instrumental: algunas notas..., p. 194.

59 Montoro Chiner, María Jesús y Hill Prados, María Concepción. Responsabilidad patrimonial de la Administración y contrato de seguro. Barcelona: Atelier, 2002, p. 102.

60 Cassagne, Juan Carlos. Derecho Administrativo. Buenos Aires: Abeledo-Perrot, 1998, T. I, p. 364.

61 Ballesteros Fernández, Ángel. La responsabilidad patrimonial de los entes instrumentales de la Administración y su transmisión a la entidad matriz..., p. 571.

${ }^{62}$ Delpiazzo, Carlos E. Estudios sobre la Responsabilidad de la Administración..., pp. 31 y sgtes.

63 Delpiazzo, Carlos E. «Recepción de los principios generales de Derecho por el Derecho positivo uruguayo». En: Actas del VII Foro Iberoamericano de Derecho Administrativo. La Coruña: Netbiblo, 2008, pp. 607 y sgtes.; y En: Brito, Mariano R.; Cajarville Peluffo, Juan Pablo; Delpiazzo, Carlos E. y Duran Martinez, Augusto. Los principios en el Derecho Administrativo Uruguayo. Montevideo: A.M.F., 2009, p. 47.

${ }^{64}$ Hauriou, Maurice. Principios de Derecho Público y Constitucional. Madrid, 1968, p. 53.

65 Jeanneau, Benoit. Les principes généraux du droit dans la jurisprudence administrative. París: Sirey, 1954, p. 134.

66 Delpiazzo, Carlos E. Texto Ordenado de Procedimiento Administrativo. Montevideo: F.C.U., 2008, p. 15.

67 Delpiazzo, Carlos E. Derecho Administrativo Uruguayo..., pp. 7 y 178.

68 Duguit, León. Traité de Droit Constitutionnel. T. III. París, 1930, pp. 732-733. 
69 Santamaría Pastor, Juan Alfonso. Principios de Derecho Administrativo General. T. I. Madrid: Iustel, 2005, pp. $86-87$.

${ }^{70}$ Parejo Alfonso, Luciano y otros. Manual de Derecho Administrativo.... Vol. 1. 4ª edición, p. 68.

${ }^{71}$ Urosa Maggi, Daniela. Tutela judicial frente a la inactividad administrativa en el Derecho español y venezolano. Caracas: FUNEDA, 2003, pp. 89-90.

72 Santamaría Pastor, Juan Alfonso. Principios de Derecho Administrativo General..., T. I. p. 88.

73 Delpiazzo, Carlos E. «Responsabilidad del Estado y tutela jurisdiccional efectiva». En: Estudios Jurídicos en homenaje al Prof. Mariano R. Brito. Montevideo: F.C.U., 2008, pp. 967 y sgtes.

${ }^{74}$ González Pérez, Jesús. El derecho a la tutela jurisdiccional. Madrid: Civitas, 2001, p. 57.

75 Delpiazzo, Carlos E. «Medidas cautelares en el Derecho Administrativo». En: Curso sobre medidas cautelares. Montevideo: F.C.U., 1999, pp. 207 y sgtes.; «Medidas cautelares frente a la Administración». En: Anuario de Derecho Administrativo. T. XV. pp. 63 y sgtes.; e «Importancia de las medidas cautelares en los contenciosos administrativos». En: Tribuna del Abogado. $\mathrm{N}^{\circ} 155$, Montevideo, 2007, pp. 28 y sgtes.

${ }^{76}$ Cajarville Peluffo, Juan Pablo. «Incumplimiento de sentencias y responsabilidad estatal». En: Estudios Jurídicos en homenaje al Prof. Mariano R. Brito. Montevideo: F.C.U., 2008, pp. 925 y sgtes.; y Durán Martínez, Augusto. «Ejecución de la sentencia anulatoria en el contencioso administrativo uruguayo». Rev. La Justicia Uruguaya. T. 136. Sección Doctrina, pp. 141 y sgtes.

77 Delpiazzo Antón, Gabriel. Tutela jurisdiccional efectiva frente a la Administración. Montevideo: U.M.,2009, pp. 68 y sgtes.

78 Ariño Ortiz, Gaspar y otros. Principios de Derecho Público Económico. Granada: Comares, 1999, pp. 66 y sgtes.

${ }^{79}$ Gordillo, Agustín A. Tratado de Derecho Administrativo. Tomo I. 4ª edición Buenos Aires: Fundación de Derecho Administrativo, 1997, pp. II-18.

80 Fernández, Tomás Ramón. Panorama del Derecho Administrativo al comienzo de su tercera centuria. Buenos Aires: La Ley, 2002, p. 23.

81 Fernández, Tomás Ramón. Panorama del Derecho Administrativo al comienzo de su tercera centuria..., p. 27.

82 Rodríguez-Arana Muñoz, Jaime. «La vuelta al Derecho Administrativo. A vueltas con lo privado y lo público». Rev. de Derecho de la Universidad de Montevideo. Año IV. № 7. Montevideo, 2005, pp. 89 y sgtes.

83 Cassese, Sabino. «El problema de la convergencia de los Derechos administrativos». Rev. Actualidad en el Derecho Público. № 5, Buenos Aires, 1996, pp. 3 y sgtes.

${ }^{84}$ Muñoz Machado, Santiago. La Unión Europea y las mutaciones del Estado. Madrid: Alianza, 1993, p. 128.

${ }^{85}$ Cassese, Sabino. La globalización jurídica. Madrid: Marcial Pons, 2006, pp. 23 y sgtes.

${ }^{86}$ Gimeno Feliu, José María. «La necesaria interpretación subjetivo funcional del concepto de poder adjudicador en la contratación pública». Rev. de Administración Pública. № 151. Madrid, 2000, pp. 425 y sgtes.

87 Gimeno Feliu, José María. El control de la contratación pública. Madrid: Civitas, 1995, pp. 115 y sgtes.

${ }^{88}$ Meilan Gil, José Luis. La estructura de los contratos públicos. Madrid: Iustel, 2008, pp. 157 y sgtes.

89 Álvarez de Toledo Quintana, Lorenzo. Abuso de personificación, levantamiento del velo y desenmascaramiento. Madrid: Colex, 1997, p. 17.

90 Olivera Garcia, Ricardo y Olivera Amato, Juan Martín. «El disregard of legal entity en la jurisprudencia». Anuario de Derecho Comercial. Montevideo, 2004, T. 10. pp. 360 y sgtes.

91 Ortiz Vaamonde, Santiago. El levantamiento del velo en el Derecho Administrativo. Madrid: La Ley, 2004, pp. 161 y sgtes., 455 y sgtes., y 499 y sgtes.

92 Ortiz Mallol, José. La relación entre la entidad matriz y la instrumental: algunas notas ..., p. 193.

93 Caruz Arcos, Eduardo. «La contribución del Derecho comunitario a la definición de la fundación privada de influencia pública dominante como ente instrumental de las administraciones públicas». En AA.VV. La Administración Instrumental. VIII Jornadas del Gabinete Jurídico de la Junta de Andalucía. Sevilla, 2005, p. 14.

94 Parejo Alfonso, Luciano. El juego de la técnica del levantamiento del velo el caso de personas jurídicas creadas por o en mano de la Administración pública..., p. 31.

95 Delpiazzo, Carlos E. Dignidad humana y Derecho. Montevideo: U.M., 2001, pp. 27 y sgtes.

${ }_{96}$ González Pérez, Jesús. La dignidad de la persona y el Derecho Administrativo. Curitiba: Juruá, 2007, p. 13. 